\title{
Management of educational institutions with inclusive education based on innovative technologies
}

\author{
Tetiana Vakaliuk $^{1,2, *}$, Inesa Novitska $^{3, * *}$, Igor Verbovsky ${ }^{3, * * *}$, Tetiana Rozhnova $^{4, * * * *}$, and Valerii Kontsedailo $^{5, \dagger}$ \\ ${ }^{1}$ Zhytomyr Polytechnic State University, 103 Chudnivsyka Str., Zhytomyr, 10005, Ukraine \\ ${ }^{2}$ Institute of Information Technologies and Learning Tools of the NAES of Ukraine, 9 M. Berlynskoho Str., Kyiv, 04060, Ukraine \\ ${ }^{3}$ Zhytomyr Ivan Franko State University, 40 Velyka Berdychivska Str., Zhytomyr, Ukraine, 10008 \\ ${ }^{4}$ State Higher Educational Institution "University of Educational Management”, 52 A, Sichovykh Striltsiv Str., Kyiv, 04053, Ukraine \\ ${ }^{5}$ Inner Circle, Nieuwendijk 40, 1012 MB Amsterdam, Netherlands
}

\begin{abstract}
The paper analyzes the theoretical and methodological basis of the organization of management of educational institutions, especially in the organization of management of educational institutions with inclusive education based on innovative technologies. Lack of conceptual and operational-practical aspects of management of educational institutions, which leads to spontaneity in the mechanisms of innovation management, lack of definition of target and value aspects of such changes, necessitates the development of a new model of management of educational institutions that would take into account new trends in inclusive education, provided favorable conditions for innovation, asserted humanistic values as a priority in the development of innovative educational space. The paper presents and scientifically substantiates the model of management of educational institutions with inclusive education based on innovative technologies, as well as key components of the organization of the educational process, which determine the areas of management in educational institutions. The algorithm of the introduction of managerial innovative technologies is offered, and also the innovative technologies which are necessary for the realization of the model of innovative management of educational institutions with inclusive training are systematized and analyzed. Analyzing the results of the experiment, it can be argued that innovative technologies are a necessary condition for successful innovation management. The introduction of innovative educational management requires an analysis of all stages of innovation, from the process of preparation to the introduction of innovations; finding out the direction of pedagogical processes, trends in their development, compliance with goals, identifying potential opportunities for the system.
\end{abstract}

\section{Introduction}

The modern theory of education requires a rethinking of the place and existence of man in education, in particular, requires a new dimension and realization of its qualitative potential. This, in turn, requires the integration of education into the world, changes in the management system in educational institutions, the introduction of innovation, focus on universal and national values, the transition to a new educational model based on the humanistic paradigm of learning, education, and personal development. The management system of an educational institution is a powerful regulator of innovation processes in the education system, a strategic link in the development of an educational organization.

Of particular importance in such conditions is the management of innovation processes that characterize the level of change in the educational organization, their focus, values. This approach determines the orientation of the mod-

\footnotetext{
*e-mail: tetianavakaliuk@gmail.com

**e-mail: inesanovicka@gmail.com

***e-mail: super_iagrik2011@ukr.net

****e-mail: rognova_te65@ukr.net

†e-mail: valerakontsedailo@gmail.com
}

ern education system to increase the index of inclusion in society and education.

At the same time, the lack of conceptual and operational-practical aspects of management of educational institutions leads to spontaneity in the mechanisms of management of innovation processes, the insufficient definition of target and value aspects of such changes. This, in turn, has negative consequences for reforming the education system. Therefore, there is an urgent need to develop a new model of management of educational institutions, which would take into account new trends in strategies for inclusive education, provide favorable conditions for innovation, affirm humanistic values as a priority in the development of innovative educational space. The urgency of this problem is evidenced by both research and surveys of managers, their deputies on the opportunities and effectiveness of innovative technologies in management to improve the education system based on innovative technologies and create an innovative educational space for students with special educational needs.

Recently, many scholars are paying more and more attention to the issues of inclusive education and the intro- 
duction of innovative technologies in the educational process.

The issues of democratic principles in education, its reorientation, an affirmation of spiritual values of national education, socialization of inclusion, and introduction of the system of inclusive education are revealed in the works of V. I. Bondar [1], V. A. Gladush [2] and others. Also, V. I. Bondar studied inclusive education as a sociopedagogical phenomenon [1], V. A. Gladush considered postgraduate pedagogical education of speech pathologists in Ukraine [2].

The problems of inclusive education have recently been of interest to more and more scientists [3-7]. In particular, L. Daniela and M. D. Lytras are considered educational robotics for inclusive education [8], J. L. Geldenhuys and N. E. J. Wevers investigated ecological aspects influencing the implementation of inclusive education in mainstream primary schools in the Eastern Cape (South Africa) [9], A. W. McCrimmon studied inclusive education in Canada (issues in teacher preparation) [10], S. Chhabra, R. Srivastava and I. Srivastava learned the perceptions of school teachers on inclusive education in Botswana [11].

Also, M. P. Opoku, J. F. Agbenyega, W. K. Mprah, J. McKenzie and E. Badu studied perspectives of special educators [12], D. Donohue and J. Bornman considered the challenges of realizing inclusive education in South Africa [13], N. Muthukrishna and P. Engelbrecht considered decolonizing inclusive education in lower-income countries (Southern African educational contexts) [14].

However, despite the significant contribution of the above scientists, it should be noted that the issue of management of educational institutions with inclusive education based on innovative technologies is especially relevant today. Currently, the education system of Ukraine needs to improve governance mechanisms to establish and ensure an inclusive educational space that will be comfortable for all participants in the educational process and will allow modern society to move to international inclusive space. Today in the country, according to statistics, every second child is born with one or another deviation, which further requires the educational institution to reformat the training system so that such a child does not learn differences and be a full member of society in which it develops and grows. Accordingly, this leads to a reformatting of the management system in the educational institution.

The purpose of the work is to theoretically substantiate and practically test the effectiveness of the model of management of educational institutions with inclusive education based on innovative technologies.

\section{Research methods}

In this research was used methods, such as: theoretical: method of analysis, comparison, a generalization of scientific data from psychological and pedagogical sources to determine the purpose, content, methods, forms, ways to improve and optimize the management of educational institutions with inclusive education based on innovative technologies; pedagogical modeling to build a model of management of educational institutions with inclusive education based on innovative technologies; empirical: questionnaires, interviews, interviews; statistical: a quantitative and qualitative analysis of research performance indicators; experimental: pedagogical experiment.

The research methodology involved the introduction of some scientific principles and approaches. Thus, the following approaches were used: synergetic, competence, personality-oriented, systemic, acmeological, activity, technological, task, innovative, adaptive.

Implementation of a systematic approach in the development of a model of management of educational institutions with inclusive learning based on innovative technologies takes into account the focus on creating a flexible, dynamic, democratic management system that uses variable management decisions, predicts results, includes innovative management mechanisms related to optimization management units adapted to the rapidly changing requirements of society and education.

Adaptive and activity approaches in the implementation of the presented model allow to consider the management process based on innovative technologies as a self-developing system, providing processes of improvement and development of collegial forms of management, unity of management and co-management, the formation of new relations between the educational institution and external environment. establishment of new forms of selfgovernment.

It should also be noted that from the standpoint of synergetic and problem-based approaches, the modernization of the management of educational institutions is possible through the active use of both internal reserves and opportunities that determine the conditions of a changing environment.

At the forefront is the technological approach, which fully reveals management by technologization of connections and means of the interaction of all participants in the educational and management processes, which significantly improves the overall performance and expands opportunities for the introduction of innovative management technologies.

Implementation of the innovative approach provides conditions for systemic innovative changes in the activities of such institutions aimed at its development and improvement, promotes the introduction of new content and forms of management, integrated methods, information and communication, and interactive technologies of teaching and educating students, building a modern management structure, improves organizational and professional culture. The application of competence and personalityoriented approaches to the management of such educational institutions based on innovative technologies reflect the interconnected innovative individual activities of management entities, identify socially significant positions of the individual in the team, taking into account not only professional requirements but also personal needs of each participant.

The implementation of the proposed model involved the introduction of such principles as continuity, centralization, and decentralization, realism, dosage, con- 
cretization, democratization, humanization, motivation, system, integrity, consistency and continuity, differentiation and individualization, environmental compliance, competence, integrity, integrity and collegiality, a rational combination of rights, duties and responsibilities, the presence of leaders focus on the need for continuous application of pedagogical innovations in inclusive education, management theory, regulatory support. Also, we have identified the basic principles of management, namely: the optimal ratio of centralization and decentralization in management; unity of unity and collegiality in management; a rational combination of rights, duties, and responsibilities in management; priority and systematization in management; replacement, redistribution, and division of labor in management, etc. This allowed us to orient the organizational structure of an educational institution with inclusive education, which includes some sectors: administrative, medical - psychological - health, educational - educational, educational - methodical (educational), inclusive resource, information - monitoring.

\section{Results}

At the beginning of the study, a survey of 115 managers and their deputies was conducted. To the question "Do you use innovative technologies in your practice?" 58\% of teachers answered "Yes", the dominant answer was "Partially" - 67\%, and 20\% answered "Yes" and get positive results (figure 1). The analysis of the survey showed that most of them are aware of the need to change the management system of educational institutions with inclusive education.

It was also noted that in some educational institutions, for many teachers, innovative technologies are a motivating factor for the introduction of elements of inclusive education, which facilitates the solution of many problems of children with special educational needs. Such technologies are also effective in training high school students who will soon cross the school threshold [15].

Timely introduction of innovation in the training of students with special educational needs expands learning opportunities, allows better learning curricula, develops skills for continuing education in higher education, and further expands their employment opportunities, thus creating additional conditions for the socialization of inclusion in society.

However, there are several serious problems in the management of modern educational institutions with inclusive education based on innovative technologies. Despite the call dynamics of the use of innovative technologies among the representatives of the teaching staff, the administration of the educational institution feels a sharp opposition of the team to the introduction of innovations. This is due to their orientation and traditional forms of work, due to the lack of motivation of some teachers for professional growth. Some leaders noted that, as a rule, the teaching staff at a fairly low level introduces innovative technologies in the educational process, due to lack of skills in working with information and communication technologies, they are not always ready to create an inclusive educational environment. turn creates serious obstacles in establishing a management system in educational institutions with inclusive education based on innovative technologies.

\subsection{Model of management of educational institutions with inclusive education based on innovative technologies}

Our study presents a model that is related to the direct practice of management in educational institutions with inclusive education, based on the introduction of innovative technologies. This model is built not only taking into account the theoretical content but also based on concrete and practical content of the work of educational institutions with inclusive education in the Zhytomyr city and Zhytomyr region.

The pedagogical content of our model is that it allows you to identify relevant and promising tasks related to the management of educational institutions with inclusive education based on innovative technologies, identify, study and scientifically justify the socio-pedagogical conditions for management and identify some innovative technologies educational management.

Developing a model of management of the teaching staff of an educational institution with inclusive education, which promotes the management process based on innovative technologies, emphasized that the administration of the educational institution influences the teaching staff, students and parents through management decisions and delegation of authority to the teaching staff.

Based on the above provisions, a model of managing the activities of the teaching staff of the secondary school to form a healthy lifestyle in high school students was created.

The theory of modeling interpreted by O. Tur [15] according to the following algorithm: identification of significant factors that may affect the outcome of solving the problem; selection of those factors that can be described quantitatively; combining factors on common grounds and reducing their list; establishing a quantitative relationship between the elements of the process. Also, this model allows you to integrate the efforts of not only managers but also educators, psychologists, social educators, other professionals involved in the organization and provided the educational process.

In the context of the researched problem, our model (figure 2) includes the following structural units: target, methodological, semantic, operational-activity, and evaluation-effective. These components of the model are implemented through management innovative technologies, taking into account socio-pedagogical conditions, through various forms and types of management actions, in the process of which the expected result of management of educational institutions with inclusive education is achieved.

The target unit defines the purpose of the expected results and requires the introduction of management modeling technologies, analysis of experience and resources of 


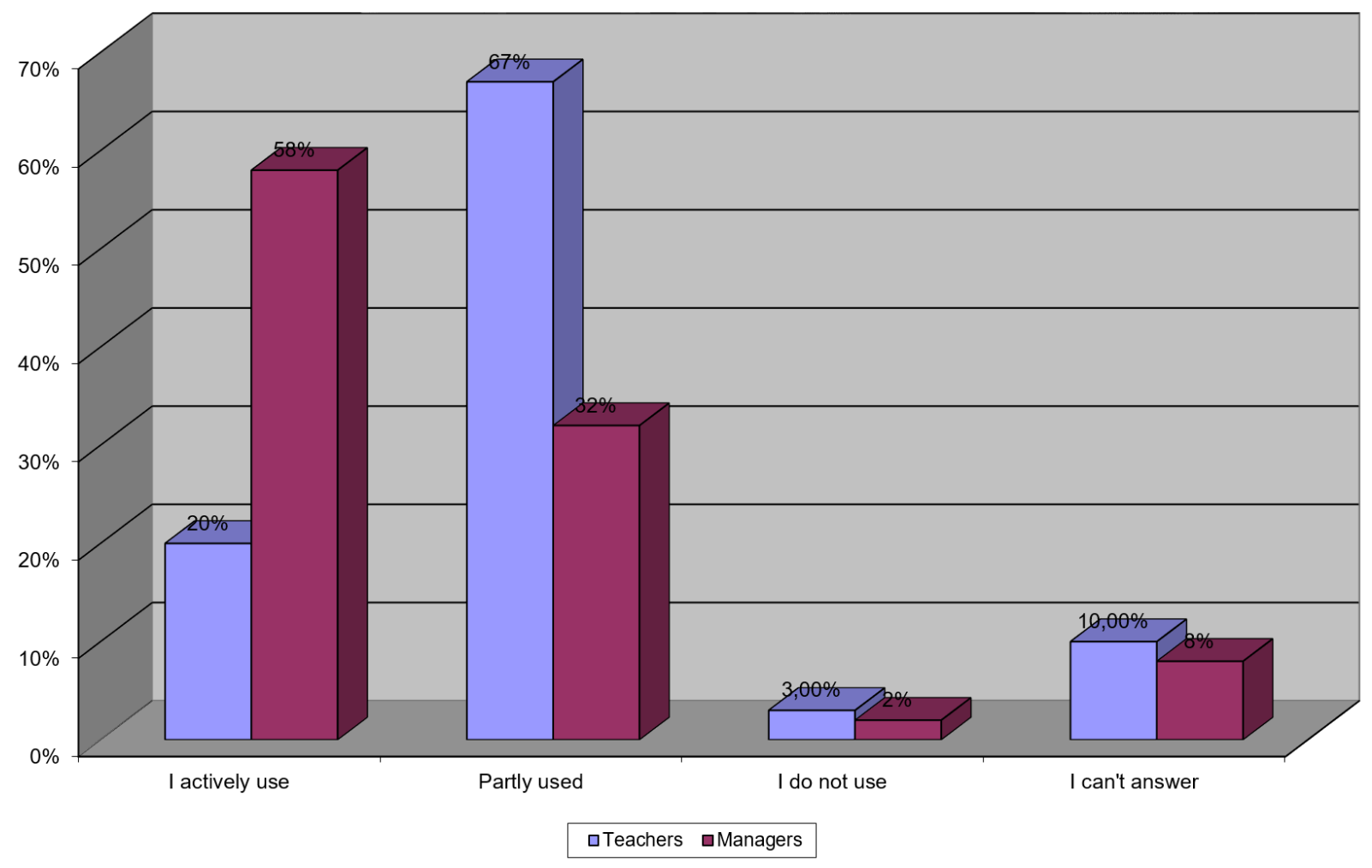

Figure 1. Diagram of the distribution of respondents' answers to the question: "Do you use innovative technologies in your practice?"

the institution, closely related to other components of the model, in particular, determines their structure and content.

The methodological unit covers the principles and scientific approaches to the management of educational institutions with inclusive education based on innovative technologies. Thus, the main approaches are defined as synergetic, competence, personality-oriented, systemic, acmeological, activity, technological, task, innovative, adaptive.

Implementation of a systematic approach in the development of a model of management of educational institutions with inclusive learning based on innovative technologies takes into account the focus on creating a flexible, dynamic, democratic management system that uses variable management decisions, predicts results, includes innovative management mechanisms related to optimization management units adapted to the rapidly changing requirements of society and education.

Adaptive and activity approaches in the implementation of the presented model allow to consider the management process based on innovative technologies as a self-developing system, providing processes of improvement and development of collegial forms of management, unity of management and co-management, the formation of new relations between the educational institution and external environment, establishment of new forms of selfgovernment.

It should also be noted that from the standpoint of synergetic and problem-based approaches, the modernization of management activities of educational institutions with inclusive education is possible through the active use of both internal reserves and opportunities that determine the changing environment.

At the forefront is the technological approach, which fully reveals management by technologicalization of connections and means of the interaction of all participants in the educational and management processes, which significantly improves the overall performance and expands opportunities for the introduction of innovative management technologies.

Implementation of the innovative approach provides conditions for systemic innovative changes in the activities of educational institutions with inclusive education, aimed at its development and improvement, promotes the introduction of new content and forms of management, integrated methods, information and communication and interactive technologies of teaching and educating students, building modern management structure, improves organizational and professional culture. The application of competency and personality-oriented approaches to the management of educational institutions with inclusive learning based on innovative technologies reflects the interconnected innovative individual activities of management entities, reveals socially significant positions of the individual in the team, taking into account not only professional requirements but also personal needs.

Thus, the scientific approaches used in the study provide a scientific understanding of the management model of educational institutions with inclusive education based on innovative technologies. 


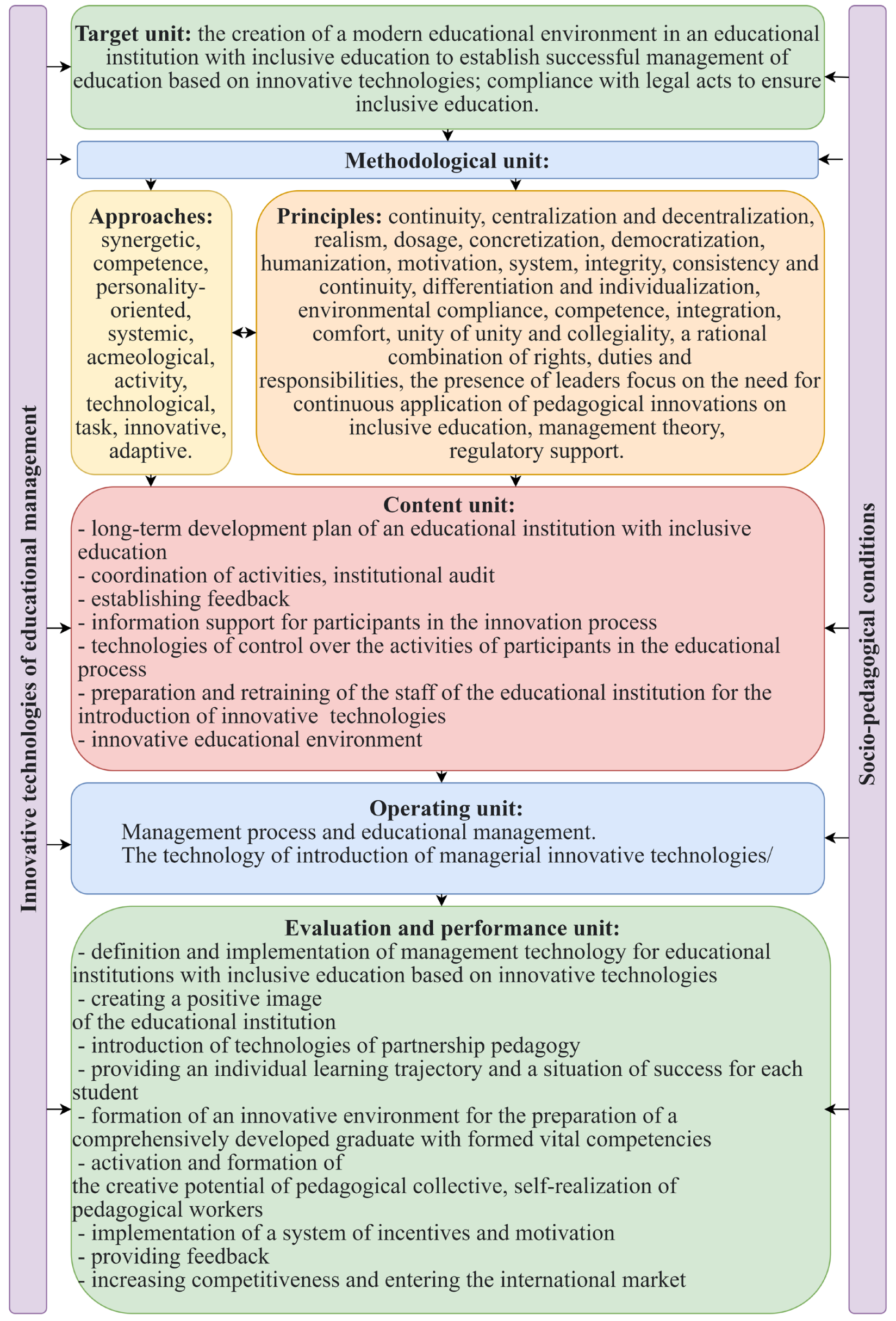

Figure 2. Model of management of educational institutions with inclusive education based on innovative technologies 
Given the management of educational institutions with inclusive education, we focused on such innovative principles as continuity, centralization, and decentralization, interdisciplinary approach, concretization, democratization, humanization, motivation, systemic, integrity, competence, integration, leading unity, a rational combination of rights, duties, and responsibilities, the presence of managers focus on the need for continuous application of pedagogical innovations on inclusive education, management theory, regulatory support.

The principle of continuity allows us to take into account that the quality of innovation management depends mainly on professional competence, personal qualities, erudition, spiritual culture, and creative attitude to the work of teachers in a cyclical process. Besides, the implementation of this principle also involves continuous training of teachers - "lifelong learning", "education without borders", "access to all levels of education", "fair access to education".

Accordingly, the principle of realism, which means the perception of reality through a system of relationships that act as an external force influencing the feelings, thoughts, and behavior of the child, serves as a source of replenishment of his social experience. Regarding the principle of environmental friendliness, it is he who ensures the compliance of all management activities of educational institutions with inclusive education based on innovative technologies for the formation of an appropriate lifestyle to the age and individual characteristics of each student. The use of the appropriate amount of information thought out in terms of volume and complexity, which can focus the attention of all participants in the educational process on the relevant issue ensures the implementation of the principle of dosage.

It is expedient to introduce the principle of comfort, which means the creation in the educational institution of such a social and psychological health-preserving educational environment, which is convenient for organizing the activities of each participant in the educational process of an educational institution with inclusive education. Implementation of the principles of differentiation and individualization involves the need to take into account age, gender, health, traditions, awareness, needs and provides differentiation of content, forms, and methods of work based on spiritual, social, mental, and physical health, motives and other characteristics of the individual. Taking into account the principles of sequence and continuity includes phasing and logical sequence of steps in the management process in a modern educational institution based on innovative technologies.

The principle of innovation of the management process is characterized by a focus on constant updating of the management process through the use of innovative technologies, structural and functional improvement, encouragement of initiative and innovation, which is a necessary condition for creative development, search for new approaches to training, education, management.

The principle of motivation for innovation is characterized by systematic stimulation of complex long-term innovation process in educational institutions with inclusive education, providing conditions for experimental activities using professional and creative opportunities of teachers, support of innovative teachers, stimulating innovative initiative, initiative, and independence of management.

The principle of rational combination of rights, duties and responsibilities and the introduction of innovative technologies is combined with the principle of democratization in management, provides personal functional responsibility of participants in educational and management processes for their part of innovation, combination with collective forms of work, a delegation of powers to innovate within additional functional responsibilities at different stages of creation and implementation of innovation.

These principles reflect the constant trends and patterns of innovation management, as well as emphasize the importance and relevance of the problem.

To implement the model, some specific tasks were identified: to reconcile the goals of the development of the educational institution with inclusive education as a social institution with the goals of each participant in the educational process. It is important to guide the teaching staff on the path of the introduction of innovative technologies and to determine the guidelines for success in the process of innovation, common values, positive motivation for the change of all participants in the educational process. It is necessary to determine the priorities for education in today's inclusive education. The motivation system plays a key role. It is necessary to motivate school teachers to exchange experiences in the form of round tables, master classes, seminars, press releases, to create an electronic page on the school portal on the problem of research. An important point is the moral support and motivation of members of the teaching staff in various areas of inclusive education. The main tasks include systematic professional development of teachers, taking into account the uniform requirements for the organization, and effective activities of the teaching staff. It is necessary to define a system of delegation and involve teachers in all stages of management. Aspects of innovation should also be introduced into the work of methodological associations of school teachers. It is important to monitor the satisfaction of all participants in the educational process and internal audit of management activities.

Fulfillment of these tasks will allow to determine the state of innovative development of educational institutions and to obtain some indicators of management efficiency based on innovative technologies. In particular, indicators of development of the innovation space of the educational institution: conditions, condition, the functional efficiency of all subjects of the educational process, the degree of openness of the institution, communication links, quality of innovative products. Among the indicators of the results of the educational process is determined by the level of education and upbringing of students, the level of socialization of inclusion, the level of social, motivational, and functional competence. Indicators of the level of management of innovation processes: the level of forecasting changes, the level of organization, regulation, and correction of innovation, the level of examination of innovations. 


\subsection{Characteristics of innovative technologies that are necessary for the implementation of the model of innovative management of educational institutions with inclusive education}

The technology of the introduction of new in the course of the decision of actual problems of an educational institution. This technology makes it possible to solve the management task - to ensure the focus of innovation to address specific problems that exist in this institution, and to overcome the inertia of the institution. This technology includes five main stages. The name of each stage reflects its purpose and place in the system of management actions:

1) preparation of innovation,

2) the introduction of a new one,

3) organization of teachers' activities for mastering and applying the new,

4) preliminary results of innovation activity,

5) dissemination and improvement of new experience.

Innovation project management technology. Management task - optimization of management actions in the process of managing an innovative project. This technology encourages the maintenance of the independence of the objects of management, which is provided by the head in the form of an order or instruction, in which part of the managerial powers is transferred to the appropriate group of teachers to perform any new responsibilities. As a rule, such obligations are the task of developing or implementing pedagogical innovations, and groups that are partially independent (perhaps even with a separate current account in the bank) are groups of designers of pedagogical innovations who report directly to the scientific and methodological council, work together with scientific consultants and scientific institutions. In this case, almost every group of creative teachers can partially become the subject of management.

The algorithm includes three main stages: preparation of innovation, testing of innovative ideas, and consolidation of innovation in vocational education. It reflects the process of making management decisions made as to the final steps of each stage.

The technology of analysis of experience, problems, and resources of the educational institution. Management tasks - identifying the specifics of a particular institution, its need for renewal, its innovative capabilities. This technology allows you to design the long-term development of each institution based on innovation, to take into account its features, reflected in the triad "experience - problems resources".

When using this technology:

- experience of the teaching staff - is divided into positive and negative, traditional and innovative, original and borrowed, single and repetitive;
- differentiated by the hierarchical level in the organizational structure of the educational institution and the direction of work in which it exists;

- relevant problems for this educational institution - are determined based on the ratio of the institution's experience with current problems of society, students, parents, teachers, employers;

- are considered in conjunction with the experience of the institution, while identifying contradictions in the work that needs to be overcome;

- in the structure of resource provision of the educational institution are allocated financial, logistical, personnel, information and structural and organizational resources of the institution, which, in turn, are divided into internal and external;

- analytical conclusions are based on the direct and feedback links established in the process of analysis between the experience, problems, and resources of the institution.

Collective planning technology. Management tasks the organization of collective planning of work, development of the innovative project in the group; implementation in the process of planning the needs and opportunities of participants in future innovation.

An innovative approach to creating the preconditions for the introduction of innovative CL technology is the development of a business plan and a clearly defined strategic goal, which provides what the educational institution will do to achieve its goals. The main characteristic of the strategic goal is future orientation.

Marketing activity should be a component of business planning. It is one of the features that distinguishes business planning from traditional types of planning. Marketing analysis helps to assess the "market" opportunities of the institution, i.e. the ability to provide exactly those educational services in qualitative and quantitative terms that are needed today in the labor market.

The basis of marketing activities is to monitor target audiences. The target audiences are students, entrants, graduates, and employers. The reason for this separation of segments is that it must work according to a market system, which is a set of interconnected markets: the education market and the professional market provides educational services to consumers, the consumers of which are physical entities (students) and at the same time offers the products of its activities (graduates - skilled workers) to the labor market, the consumers of which are legal entities (enterprises, organizations, and institutions of various industries).

As a result of collective planning, a set of tasks is formed, the implementation of which ensures the achievement of the result "seen" at the beginning of the project, and a group of like-minded people is created, each of whom represents joint work and role.

The technology of long-term development of the basic innovative idea. Management task - to ensure the maximum realization of the educational potential of innovative 
ideas in the long-term development of the educational institution by enriching the common idea with partial innovations.

The main stages of technology implementation:

1. Preparatory stage (detailed project development).

2. The formation of innovation (formation of the contingent of participants in innovation activities - students and teachers; the beginning of the implementation of innovative educational programs and projects of the educational process).

3. Development of an innovative idea (gaining experience of the subject activity, improvement of activity, improvement of quality of its results, development of new kinds of activity, the formation of traditions, the achievement of the social usefulness of projects, development of co-management).

4. Stable functioning (accumulation of experience of the traditional activity, acquisition of stability by the system).

5. Updating (crisis prevention and overcoming stagnant trends).

The fifth stage should again be followed by the stages of development (3rd) and stable development (4th), which allow to multiply and improve the work experience, connecting the new with the traditional and selecting the most effective forms, methods and techniques. In the future, the consistent cyclical implementation of the stages of renewal, development, and stable operation provides longterm development of the basic innovation idea.

Technology to support educational initiatives and pedagogical creativity. Management task - to provide the necessary conditions for the formation, promotion, and implementation of productive innovative ideas by the subjects of innovative activity (within the educational institution and in interaction with the environment).

Management support in this technology is implemented through a set of measures to intensify innovation. Support covers various stages of educational initiatives and pedagogical creativity: idea formation, idea nomination, project development, approbation, implementation. At each stage, support acquires its specificity due to the uniqueness of management tasks and a combination of management support techniques.

Management modeling technology. Management task - optimization of the process of creating and applying management models as ideal systems. It allows you to deeply comprehend the actual existing or newly formed objects of management, to predict their development.

The implementation of this technology includes an algorithm: statement of the problem for which the model is created; construction of the model, which begins with the definition of the main purpose of the model, as well as "input" (necessary data, resources, conditions, assumptions) and "output" (desired and achieved result); introduction of this model in management; checking the effectiveness of the implementation of the model according to the criteria of management evaluation; model update (performed if the required data about the object or new information appears, which should also be included in the model).

The technology of self-correction of pedagogical activity. Management task - the organization of independent work to eliminate their shortcomings in the preparation and implementation of certain segments of the educational process. This technology is implemented using two main tools: a package of process tables and a self-correction algorithm. Technological tables serve as reference material and reflect the structure of professional competence in the field of elimination of pedagogical errors and allow the pedagogical worker to work on them independently.

Self-correction algorithm:

1) highlighting the shortcomings in pedagogical activities in the analysis, self-analysis;

2) work with technological tables, which takes place when performing certain operations;

3) awareness of the possible negative consequences of the error and the need to eliminate it in their work (selfmotivation);

4) finding out the reasons for the error (introspection); definition of tasks for work on error elimination (selfgoal);

5) modeling of the activity directed on elimination of an error (self-construction and self-organization);

6) practical implementation of the model of activity to eliminate the error;

7) self-analysis of the effectiveness of work on the error.

The technology of the educational and methodical game. Management task - the development of interest of teachers in innovation through the introduction of game elements in the structure of methodical work. This technology covers the development and conduct of educational and methodical games. Game development in technology begins with the creation of two models: simulation and game. The simulation model reflects the specifics of the professional activity of the specialist. It includes the goals of the activity, the subject of the game, a graphic model of the role interaction of the game participants, the system of evaluation of results. The game model creates the social context of the game, covers a set of roles and functions of players, the rules of the game, can include a script.

The technology of development of educational work. Management tasks - optimization of activity of pedagogical workers in the development of original educational business, action; ensuring the pedagogical effectiveness of the author's forms of educational work. The technology covers the following stages of development of educational work: thematic planning, preliminary (draft) planning of work, editing of the plan, final registration of the plan of educational work. Each stage is accompanied by a general algorithm for its implementation and a reminder for the teacher-beginner. 
The technology of organized innovative change of management states. Management task - optimization of the process of creating and applying innovative changes in management, which allow a deep understanding of the existing objects of management, to predict their development and implementation. This technology involves a certain system of management, which covers the stage of preparation for changing the state of the management system and the stage of their implementation.

Fundraising technologies. The development of market relations and the use of alternative sources of financing have a significant impact on the renewal of management mechanisms. Fundraising technologies are being actively introduced into the practice of modern school work. Fundraising, as a set of different methods and procedures for finding resources for the implementation of socially significant school projects, requires the head to strengthen the relationship with the external environment of the school. The effectiveness of such activities depends on the ability to optimize public relations by ensuring maximum openness of the school. Methods of organizational and stabilizing influence, organizational and technological influence, and socio-psychological ones come to the fore in the management of the school organization, which ensure effective cooperation of all those who have expressed a desire to cooperate with the school.

ICT. The technologization of all aspects of the development of the social sciences has led to changes in the technology of school management. This approach is primarily associated with the introduction of new ICT, they not only allow much more efficient processing of large amounts of information and more quickly make management decisions, but also resolve conflicts that arise between modern requirements for the functioning and development of the institution education and outdated technologies used by school principals; between the pace of development of the managerial and managed subsystems of the secondary school. However, there are often problems with the lack of management software designed for school principals, which is quite subjective due to the inability of a significant number of principals to use computers properly. On the other hand, in the context of technologicalization of educational processes, there is also a danger of underestimation, and sometimes ignoring the humanistic principles in management technologies. There is an exaggeration of the importance of virtual communications, pragmatism. Here we must emphasize the circumstances that cause this situation: the complexity of management objects and processes in the modern school, each of which is a complex, polystructural, and multifunctional dynamic system. Innovative development of society, education requires a rapid change of management and educational technologies.

\subsection{Implementation of the model of management of educational institutions with inclusive education based on innovative technologies}

The dynamics of development of the innovation space of an educational institution is characterized by the unity of external and internal environments, which requires consideration of environmental conditions. An educational institution with inclusive education is a complex open system that must constantly respond to changes in modern society, so the strategic thinking of the education manager is one of the conditions for the progressive development of an educational institution.

In the regulation of development, a significant role is played by the coordination of joint actions and management decisions, ensuring equal opportunities for selfdevelopment of each participant in the educational process. Therefore, the main features of the progressive development of innovative educational space of educational institutions with inclusive education we see the integral unity of all processes that occur in the development of educational space of the school; functional efficiency of all subjects of the educational process of the school; development of the educational space of the school-based on humanistic pedagogy and psychology.

The management of educational institutions with inclusive learning based on innovative technologies is closely related to the management of changes that are constantly taking place in the institution and require appropriate leadership. However, we have that every development implies change, but not every change is development. Scientists note that development is a change that is associated with internal restructuring, progress. Therefore, for this forward movement to be progressive, purposeful management of such a process is needed.

Since the effectiveness of the management of educational institutions with inclusive learning based on innovative technologies depends on the effectiveness of change management in the institution, we will identify objects that need constant change. Among them: the system of intra-school management, the development of the school organization, the management of the teaching staff, and the management of the development of the educational institution. The mechanisms for managing such changes include methods of involving teachers, students, parents, and the public in in-school management, which contributes to the expansion of the subjects of in-school management and strengthens the position of self-government of the school organization. Empowerment and delegation of managerial powers will strengthen the responsibility of each subject of the educational process for the changes that take place in the institution. The increase of in-school management facilities due to development processes will allow the educational institution to move from the mode of operation to the mode of development.

Ensuring the adaptability and flexibility of management organizational structures, their openness, and ability to change is important in updating management systems. Thus, the mechanisms of optimization of communication and information relations between the subjects of management, the focus on change and self-development of the subjects of internal school management play a significant role. Therefore, self-education becomes an important indicator of readiness for change on the part of both the school administration and the staff. 
Connections approaches and organizational culture are important criteria for the quality of change in the management of an educational institution. Therefore, it is important to preserve human potential in the management process, recognition of morality as a leading quality of members of the teaching staff; ensuring partnership in relations between members of the educational community, increasing informal ties in the organizational structures of the educational institution.

Management of an educational institution based on innovative technologies is determined by the level of conditions created for professional activity, the quality of the system of incentives for innovative activities, the principles of cooperation, the nature of the interaction between participants in the pedagogical process.

Important mechanisms for structuring and developing the community in the educational institution are: providing favorable conditions for the development of the innovative potential of each teacher in particular and the teaching staff as a whole; providing a diagnostic approach to identifying the creative potential of the teacher, the possibilities of his personal development and growth; optimization of incentive systems for innovation (creating a situation of success, supporting teacher initiatives; freedom of action, free choice of forms and methods of educational process), teacher involvement in research, exploration activities; expanding the scope of contacts between participants in the educational process; optimization of the development of scientific and methodological work of the institution.

Communications play an important role in the organization of management because management structures are characterized by a significant number of both external and internal connections. Therefore, the quality of the relationship between all components of the management system is one of the indicators of its focus. Connections perform not only the functions of ensuring the viability of the system, but also determine the nature, direction, functionality of the system, its ability to self-development. They ensure openness of the system, interaction between all subjects of management (administration, teachers, students, parents, the public) on the principles of partnership, cooperation.

Manufacturability in modern conditions is an important component of the quality of management. As a form of existence of activity, technology generates a system of necessary management actions and their results. Using management technologies the interaction of the head with teachers, parents, the public is carried out.

Thus, all components and components of the model of management of educational institutions with inclusive education based on innovative technologies and projected on the result: definition and implementation of technology of management of educational institutions with inclusive education based on innovative technologies; creating a positive image of the educational institution; introduction of partnership pedagogy technologies; providing an individual learning trajectory and a situation of success for each student; formation of an innovative environment for the preparation of a comprehensively developed graduate with formed vital competencies; activation and formation of the creative potential of pedagogical collective, selfrealization of pedagogical workers; implementation of a system of incentives and motivation; providing feedback; increasing competitiveness and entering the international market.

According to the specified, we offer an algorithm for the introduction of administrative innovative technologies:

1. Substantiation of the need for the introduction of management innovation technology (based on the identified problem and the formulation of the management task).

2. Decision-making on the introduction of managerial innovative technology.

3. Introduction of managerial innovative technology.

4. Tracking the process of application of innovative management techniques.

5. Analysis, control, and evaluation of the process and results of the implementation of management innovation technology.

6. Deciding to continue the use of innovative management technology or to stop working on it.

7. Recommendation for the use of innovative management technology by other managers.

8. Summarizing and analyzing the results of the introduction of innovative management technology.

Thus, this understanding of innovation processes allows us to consider innovation as a purposeful process of creating, disseminating and using innovations, where the main properties of such changes are the focus, dynamism, and new quality of the innovation product. Among the categories of the innovation process can be distinguished: the life cycle of innovations, classification of pedagogical innovations, innovative technology, innovation strategy, innovation project, innovation program. These categories have become the starting point in the system of management of innovation processes in secondary schools.

Educational institutions should be provided with highly qualified pedagogical staff, constantly take care of their level of training, regularly monitor their internships at enterprises, training courses, attend master classes, innovative exhibitions. For young pedagogical workers, it is necessary to renew and carry out training in "School of the young teacher", to create councils of mentors, to realize the project "Young teacher" that would help to adapt young workers in collective.

An important condition for the introduction of innovative technologies in the management of educational institutions is the forecasting of reversible or irreversible structural changes in the innovative socio-pedagogical environment, taking into account the law of irreversible destabilization of the pedagogical innovative environment in which the institution operates. The innovation environment cannot exist without such opportunities and collapses under the pressure of pedagogical innovations. 
As a result of management based on innovative technologies, the educational institution becomes competitive. Changes in the current socio-economic development of Ukraine require a significant increase in the creative potential and competitiveness of graduates of educational institutions with inclusive education.

\subsection{Experimental results}

The experiment on the research topic took place during 2018-2020. The effectiveness of the developed model was tested based on ten experimental educational institutions, which turned out to be the most open to change. The choice of educational institutions was carried out by the method of free choice in such a way that the experiment involved institutions of different types, differing in working conditions, some students and teachers, experience management of their leaders.

In the process of experimental work, the main empirical methods were used, namely: methods of collecting information: observation, interview, conversation; methods of information processing and analysis. We developed a questionnaire that contained questions that allowed us to assess the content of the work of the head and staff of the institution on the implementation of management based on innovative technologies. A survey of representatives of the administration, teachers on the state of the practical application of innovative technologies in the management of educational institutions with inclusive education. 115 heads of educational institutions and their deputies, 106 employees of institutions (teachers, psychologists, speech therapists, assistants), 8 parent councils of educational institutions (110 people) were involved in the survey.

Here are some survey results. To the question: "Do you implement innovative technologies in professional activities?" among the surveyed respondents, 59.6\% said, "Yes", another $23.4 \%$ - "Partially", $4.3 \%$ - answered "No", "Rather no than yes" and "Rather yes than no" $6.4 \%$ (figure 3 ).

The main reasons why today's innovative activities were identified as follows: increasing the level of interest and involvement of children in the educational process $(70.2 \%)$, interesting to create something new, unusual and better than it was $(68.1 \%)$, the possibility of individualization of educators and dissemination, implementation of own experience (53.2\%), growth and support of the image of the educational institution among parents and students $(48.9 \%)$, the possibility of creating an individual learning trajectory for students (42.6\%), improving their image (42.6\%), challenges of the information society $(42.6 \%)$, academic mobility (34\%), motivation and support of management, governing bodies (23.4\%), support and growth of image policy among other educational institutions (21.3\%), the presence of healthy competition in the team $(19.1 \%)$, a sense of self-esteem and self-affirmation $(17 \%)$, fierce competition between educational institutions $(12.8 \%)$.

In the course of answering the question: "Are the conditions for the development of innovative activity created in your institution?" only $31.9 \%$ of respondents answered
"Yes", 48.9\% answered that "Partially", 12.8\% - "Rather yes than no". This indicates the correctness of the focus of our study (figure 4).

The main reasons that create obstacles in the process of innovation were the following: insufficient awareness of innovations (44.7\%), lack of necessary theoretical knowledge $(38.3 \%)$, the predominance of traditional forms of activity (40.4\%) weak system of motivation activities on the part of management (31.9\%), the weak internal motivation of professional activity (25.5\%), limited and lack of time and effort for the application of innovative technologies (53.2\%), fear of innovation risk and change (31.9\%), lack of support from the government (36.2\%), lack of teachersinnovators in the team $(19.1 \%)$, lack of career growth $(19.1 \%)$.

In the course of the research, we were asked to rank the factors that inhibit the development of innovation in your educational institution from the least important to the most. Thus, the most important factors that create obstacles to the introduction of innovation are resistance to change on the part of the team, unwillingness to violate stereotypes of behavior and learn a new activity; orientation of pedagogical workers on traditional forms of work; features of centralization of the management of the system of general secondary education institutions; weak material and research base of the educational institution; lack of a program for the development of innovative activities of your educational institution; lack of material and other incentives for the educational institution as a whole and for administrative, pedagogical and technical staff.

To study the views of teachers on the assessment of positive changes that have taken place in the educational institution with the use of innovative technologies, the answers to the question "Have there been changes in innovation activity in your educational institution?" were analyzed. The results of the answers and their analysis allowed us to draw some conclusions about changes in the educational inclusive process with the use of innovative technologies. Namely: "Yes" $-31.6 \%$, "No" $-16.3 \%$, "Difficult to answer" - 17.7\%, "Rather yes than no" $21.3 \%$, "Rather no than yes" $-4.3 \%$, "At the stage of innovation in educational activities" $-4.1 \%$, "At the stage of innovation in management" $-4.7 \%$.

The analysis of the answers to the question that occurred with the use of innovative technologies in the management and educational process of the educational institution showed the following picture: the introduction of computer-oriented, integrated lessons (53.3\%); improving the quality of the organization and conduct of practice $(44.4 \%)$; the possibility of creating a modern educational space (37.8\%); creation of conditions for participation of pedagogical workers in all-Ukrainian and regional exhibitions, carrying out of competitions on the basis of educational institution (31.1\%); the possibility of improving and adapting curricula and programs (28.9\%); use of textbooks, manuals, methodical recommendations developed by teachers $(26.7 \%)$; increase in the index of inclusion in education (24.4\%); gradual change of management style (24.4\%); generating promising pedagogical experience (20\%); the opportunity to share experiences 


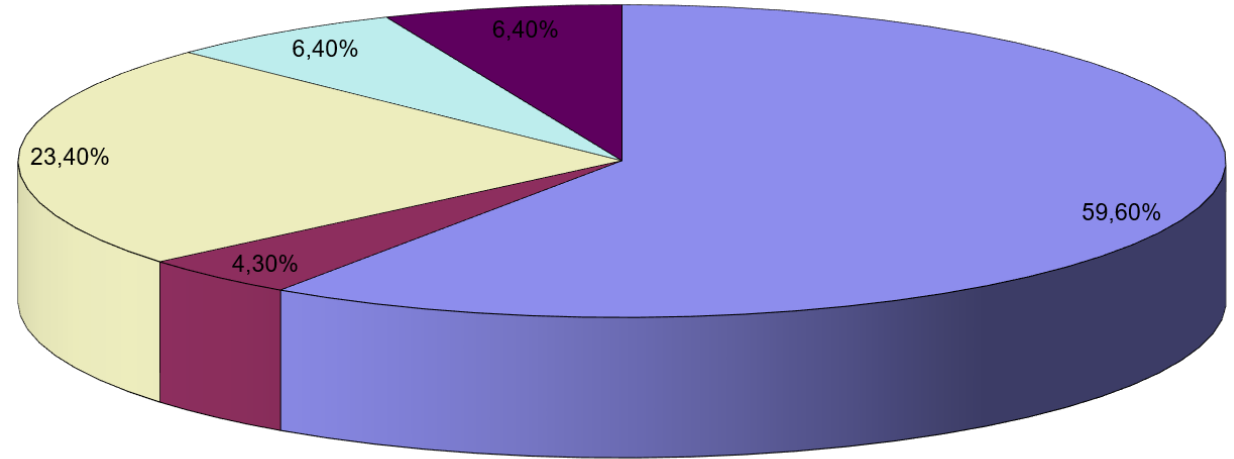

$\square$ Yes $\square$ No $\quad$ Partially $\square$ Rather no than yes $\quad$ Rather yes than no

Figure 3. Diagram of the level of introduction of innovative technologies in professional activity

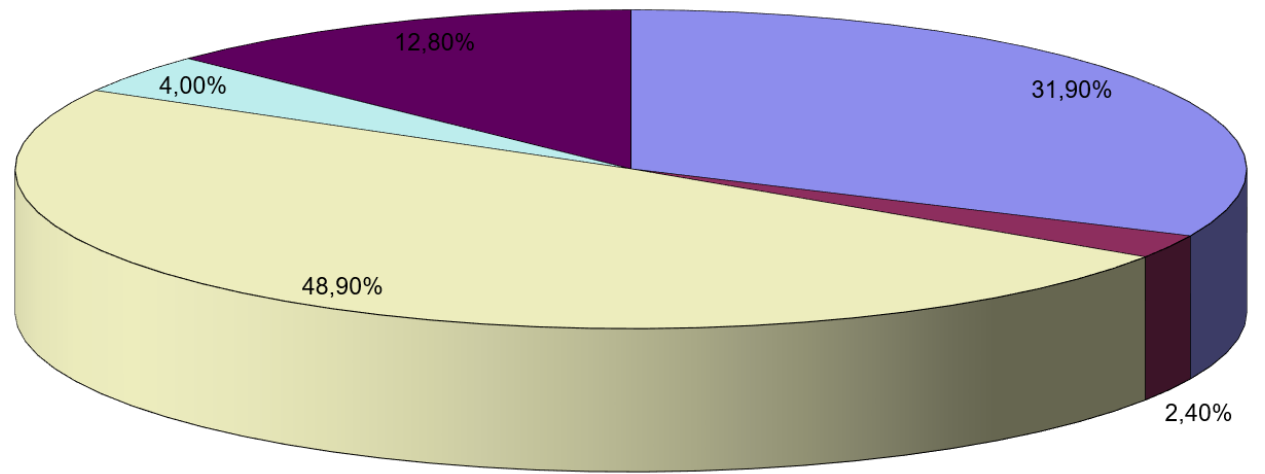

口Yes $\quad$ No $\quad$ QPartially $\quad$ QRather no than yes $\quad$ Rather yes than no

Figure 4. Diagram for assessing the availability of conditions for the development of innovation

and enter the international market for educational services (15.5\%); increased enrollment of students (13.3\%); nothing has changed $(4.4 \%)$.

In the process of implementing the model of management of educational institutions with inclusive education based on innovative technologies, we also analyzed and investigated in which category of employees of your institution the level of innovative activity has increased. Thus, from 2-3 variants of answers chosen by respondents from the list of proposed (15) it was determined that: teachers $-70.2 \%$, administration $-38.3 \%$, individual teachers $-31.9 \%$, heads of institutions $-27.7 \%$, educators or assistants or tutors $-19.1 \%$, parents $-16.2 \%$, deputy heads $14.9 \%$, psychologists or speech therapists $-12.8 \%$, social educators $-12.8 \%$.

The results of the study showed that in the management of individual heads of educational institutions with inclusive education there are indicators of innovation (use of innovative methods in the teaching system, creation and implementation of author's teaching and scientific manuals, project activities, Internet use, implemen- tation of educational innovations) and increased competitiveness (availability of additional investment, computer support of the educational and production process, growth of material and technical base, improvement of production conditions of the team, functioning of the internal system of professional growth of teachers, implementation of a personality-oriented system of professional education, provision of additional educational services).

During the study, it was determined what qualities (not more than 10 of the proposed), knowledge, skills, and abilities (not more than 6 of the proposed), necessary for the administrative staff of the educational institution to successfully implement innovative technologies.

The survey found that most managers consider it necessary to adaptive management style, develop their professional competence, learn to make non-standard decisions, self-education, initiate and implement innovative management processes. Thanks to research observations and interviews with members of the teaching staff of educational institutions of the Zhytomyr region, it was found that the 
image of the modern head of the educational institution is significantly different from that formed a few years ago.

\section{Conclusions}

Thus, at the stage of reform development of educational institutions, the ability of the head to apply the principle of innovation in management is important, which is one of the priorities and is characterized by various manifestations, namely: support for innovation, creativity, initiative, and independence of management; organized innovative change of the state of the education system with inclusive education - the transition from spontaneous innovation processes to consciously managed; information, logistical, staffing of the main stages of innovative educational processes; forecasting reversible or irreversible structural changes in the innovative socio-pedagogical environment; strengthening the sustainability of innovative educational processes; accelerating the development of innovation processes.

Thus, after analyzing the results of the experiment, we can say that innovative technologies are a necessary condition for successful innovation management. The introduction of innovative educational management requires an analysis of all stages of innovation, from the process of preparation to the introduction of innovations; finding out the direction of pedagogical processes, trends in their development, compliance with goals, identifying potential opportunities for the system.

\section{References}

[1] V. Bondar, Ridna shkola 3, 10 (2011)
[2] V. Hladush, Pisliadyplomna pedahohichna osvita defektolohiv v Ukraini: teoriia i praktyka (Postgraduate pedagogical education of speech pathologists in Ukraine: theory and practice) (Porohy, Dnipro, 2012)

[3] V. Tkachuk, Y. Yechkalo, O. Markova, CEUR Workshop Proceedings 2168, 66 (2017)

[4] Y. Nosenko, Z. Matyukh, CEUR Workshop Proceedings 1844, 459 (2017)

[5] M. Marienko, Y. Nosenko, M. Shyshkina, CEUR Workshop Proceedings 2731, 341 (2020)

[6] V. Osadchyi, H. Varina, K. Osadcha, O. Prokofieva, O. Kovalova, A. Kiv, CEUR Workshop Proceedings 2731, 263 (2020)

[7] T. Kramarenko, K. Bondar, O. Shestopalova, Journal of Physics: Conference Series 1840, 012009 (2021)

[8] L. Daniela, M.D. Lytras, Tech Know Learn 24, 219 (2019)

[9] J.L. Geldenhuys, N.E.J. Wevers, South African Journal of Education 33 (2013)

[10] A.W. McCrimmon, Intervention in School and Clinic 50, 234 (2015)

[11] S. Chhabra, R. Srivastava, I. Srivastava, Journal of Disability Policy Studies 20, 219 (2010)

[12] M.P. Opoku, J.F. Agbenyega, W.K. Mprah, J. McKenzie, E. Badu, Journal of Social Inclusion 8, 4 (2017)

[13] D. Donohue, J. Bornman, South African Journal of Education 34 (2014)

[14] N. Muthukrishna, P. Engelbrecht, South African Journal of Education 38 (2018)

[15] O. Tur, Ph.D. thesis, University of Educational Management, Kyiv, Ukraine (2013) 